A Systematic Review of Parenting in Singapore: Insights to the Culture-Specific Functions of Styles and Practices

\author{
Hoi Shan CHEUNG \\ Elinor LIM \\ Yale-NUS College
}

\begin{abstract}
Author Note
Hoi Shan Cheung https://orcid.org/0000-0002-2551-170X

Elinor Lim https://orcid.org/0000-0001-9225-0928

Correspondence concerning this article should be addressed to Hoi Shan Cheung,
\end{abstract} Yale-NUS College, 10 College Avenue West, \#01-101, Singapore 138609. This research was supported by the Ministry of Education and Yale-NUS College Start-Up Grant. The authors thank Valentino Emil Chai and Su-Min Yeo for conducting data extraction, and Rebecca P. Ang for comments on an earlier draft of this paper.

Email: hoishan@yale-nus.edu.sg

Tel: (65) 66012821 


\begin{abstract}
Cross-cultural studies on parenting have identified cultural nuances that may impact the form and functions of parenting styles and practices in different contexts. This systematic review is undertaken with the aim of identifying such nuances in an under-studied culture (Singapore), as a starting point to understand and compare the forms and functions of parenting in Asia and beyond. A review of 27 studies showed that optimal parenting styles and practices were associated with positive child development outcomes in Singapore, similar to what has been observed in Western contexts. However, some parenting behaviours that were typically considered to be sub-optimal were not invariably related to poorer child outcomes in Singapore, indicating that there may be protective cultural factors related to the interpretation of parental control. Adopting an emic approach to parenting research would deepen our understanding of the cultural generality and specificity of practices, ensuring that the design and implementation of parenting interventions are culturally appropriate and effective.
\end{abstract}




\section{A Systematic Review of Parenting in Singapore: Insights to the Culture-Specific}

\section{Functions of Styles and Practices}

Socialisation refers to the process through which individuals acquire characteristics that are valued in their society, such as behaviours, attitudes, beliefs and values that will help them function in an effective way (Gauvain \& Parke, 2010). Although socialisation occurs throughout the human lifespan, it happens most rapidly during childhood, where parents are the key agents of socialisation. Parents facilitate their children's socialisation process through various direct and indirect means. For example, parents exert a direct influence when they interact with their children, and when they create an emotional climate within the family in which the child grows. Indirect forms of socialisation include parents' choice of schools which children might attend, the neighbourhood in which they live, and the friends whom their children could spend time with.

Past research has tended to focus on the direct means of socialisation through parenting practices which are directly observable behaviours, and through parenting styles which are a set of attitudes which parents hold towards their child (Darling \& Steinberg, 1993). These attitudes are conveyed over time through parenting practices. Together, both practices and styles define the quality of the emotional climate within every parent-child relationship, such as being warm, distant or hostile. Research has further shown that parenting practices and styles are amenable to cultural differences, where the forms they take and the functions they serve may change depending on the cultural context in question (Bornstein, 2015). However, the variations are not split as simply as an East-West divide, or a superficial contrast between individualistic and collectivistic societies. Even within the "Eastern" or "collectivistic" context, there exist nuances such that some indigenous practices are more easily observed in one culture but not another (e.g., amae in Japan; Rothbaum \& Kakinuma, 2004). This highlights the theoretical and practical value of focusing on a specific 
society as the starting point in understanding the socialisation effects of parenting, before any generalisations and extensions may be made beyond that sociocultural context.

The present systematic review was undertaken with that goal in mind, by focusing on the parenting styles and practices and their associations with children's developmental outcomes in Singapore. Singapore is a city-state located in Southeast Asia, which presents an interesting multi-cultural context for the study of parenting and child development. This is mainly due to Singapore's strong Asian heritage, with ethnic Chinese (74.3\%), Malay $(13.5 \%)$, and Indian $(9.0 \%)$ forming the majority of the population (Department of Statistics, 2020). Yet, the country's history as a British colony and rapid globalisation since its independence in 1965 lend a heavy Western influence on the values and practices of the people. Moreover, English is also the lingua franca and the medium of instruction in all schools, making it easier for Western ideals and beliefs to penetrate the society. This Eastmeets-West combination results in a unique sociocultural and geopolitical landscape, which makes for a good starting point from which to compare and contrast the forms and functions of parenting with other Asian contexts and beyond. Furthermore, Singapore has become the model for educational systems around the world in recent years, gaining global recognition for the stellar academic performance of the students as they consistently ranked tops in the PISA (Programme for International Student Assessment) in reading, mathematics, and science (Education GPS, n.d.). However, Singaporean students also emerged as being among those with the highest levels of anxiety and fear of failure globally (Education GPS, n.d.). This is likely a result of Singaporeans' needs to succeed and excel in academia, as the small city-state's economic and cultural growth depend upon having a well-educated population with a global outlook. Against this backdrop, the question of how parenting styles and practices contribute to children's development is a prudent one, but has not been addressed in the literature. 
Due to a lack of a systematic understanding of parenting styles and practices and their correlates in the Singaporean context, researchers and practitioners have tended to rely on Western-centric literature, mostly based on studies conducted in North America, to inform local practices, interventions and policies. Although adaptive and effective practices that have been used and validated in other societies can be practically implemented in Singapore, these practices may or may not translate into similar benefits, in view of the different forms and functions optimal parenting practices may take across cultures (Bornstein, 2015). Hence, there is an urgent need to scrutinise the extent to which research findings on parenting in Singapore are consistent in form and function from those observed elsewhere. This would inform the development and implementation of interventions and policies, ensuring that they are culturally relevant to maximise their efficacies. Furthermore, the current systematic review would contribute to the sparse literature on Asian parenting, which is now mostly based on ethnically-homogenous samples in China, Hong Kong, Taiwan, Japan, South Korea and among Asian immigrants in the United States (see a review by Chao \& Tseng, 2002).

\section{Parenting Styles and Practices}

This review centres on parenting styles and practices by examining their correlates with child developmental outcomes, and exploring how parenting styles may set a context for the interpretation of parenting practices. According to Darling and Steinberg (1993), parenting practices are behaviours undertaken by parents in the course of performing their parental duties, and may take the form of specific, goal-directed behaviours such as exercising control on the child; or non-goal-directed behaviours such as gesturing and expression of emotion. On the other hand, parenting styles are global parenting characteristics that are a key feature of the child's environment, where parents' attitudes form the emotional climate within the parent-child relationship that accord parenting practices their meaning as they are perceived by the child. Parenting styles also modify the effectiveness of parenting 
practices by encouraging (or otherwise) a child's openness to socialisation (Baumrind, 1966). A systematic review will allow us to take a bird's eye view of the existing evidence, and interpret parenting practices with a consideration of their meaning as conveyed through the emotional climate that exists. Rather than just documenting parenting behaviours and their correlates in the Singaporean context, this review sought to compare and contrast findings from the local literature and identify culture general and specific patterns in relation to parenting and child developmental outcomes. The review thus addresses the following questions:

1. Which parenting styles and practices have been examined in Singapore, and how are they associated with children's development?

2. How do these associations compare with those observed in other Asian and Western contexts?

\section{Method}

This systematic review was guided by PRISMA (Preferred Reporting Items for Systematic reviews and Meta-Analyses) statement guidelines (Moher et al., 2009). Systematic searches were conducted on PsycINFO, PubMed, Web of Science, Scopus, and Index to Singapore Information databases. The search covered articles published between database inception and August 2020. The search terms utilised were: (Parent* OR Mother* OR Father* OR Parenting style* OR Parenting practi* OR Parenting behavio* OR Child* OR Adolescen* OR Teen*) AND Singapore*. As shown in Figure 1, identified records were first checked for duplicates and screened by title. Subsequently, relevant article titles were screened by abstracts and full texts. Articles were included if they involved:

1. children between ages 3 and 17 ; and

2. at least one parenting variable; and

3. at least one child outcome; and 
4. sample(s) from Singapore and from a typical population; and

5. empirical data published in peer-reviewed journals in English

As such, studies involving infants and toddlers as well as adolescents over the age of 17 were excluded, although those with a sub-sample of children within the age range of interest were still included. Studies with children who were not considered to be typically reflective of the general Singapore population (e.g. clinical samples, youths in gangs) were excluded, along with studies that involved adoptive parents. Additionally, studies measuring constructs indicative of parent-child relationships (e.g. parent-child closeness) rather than parenting behaviours were also excluded.

Identified papers were exported to a reference management software. Duplicates were removed. After screening each paper by their titles, abstracts and full texts, forward and backward searches were conducted on the 24 accepted articles without imposing a limit on publication date. This step yielded three new articles, bringing the final number to 27 . Results of this search process are shown in the PRISMA diagram in Figure 1. Relevant data were extracted from each study, such as study design (correlational or longitudinal), sample size, key demographic variables (e.g., age, gender, ethnicity), parenting and child outcome variables examined, the instruments used, and the relevant findings.

Study quality was measured using the Quality Assessment and Validity Tool for Correlational Studies adapted from Cowden et al. (2011). Two items were added for this review to further differentiate studies of higher quality (i.e., "was common-method variance present?", and “were all relevant statistical values reported?”). Study quality was assessed by both authors and a score ranging from 1 to 15 was assigned for each study. Studies were assigned into three groups as a function of their quality - low (score 0-5), medium (score 610) and high (score 11 and above). Disagreements on group assignment (low, medium, high) were discussed to consensus. There were two disagreements, resulting in an inter-coder 
agreement of $92.59 \%$. Most studies were rated "medium", with two rated "high" and four rated "low".

\section{Figure 1}

PRISMA Diagram for Article Selection
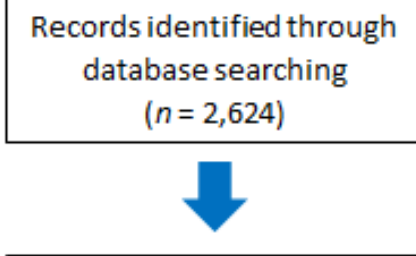

Records after duplicates

removed $(n=1,647)$

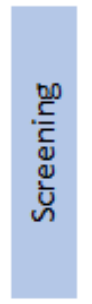

Records screened by abstract $(n=155)$

Records screened by title $(n=1,647)$

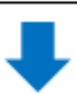
for eligibility $(n=63)$

Articles identified through forward and backward searches $(n=3)$
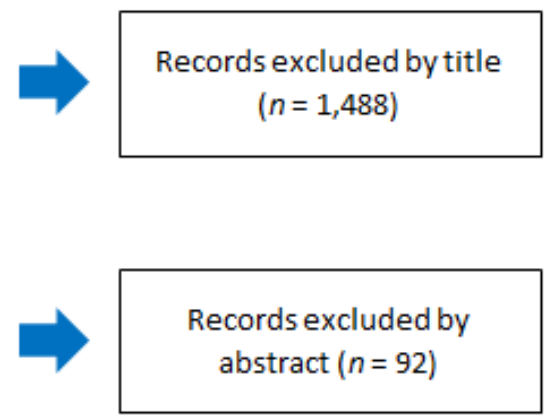
$(n=1,488)$

Articles excluded, with reasons (Total $n=39$ )

Age of participants $(n=3)$ Atypical population $(n=4)$ Dissertation $(n=1)$ Relevant variables not measured $(n=30)$

Unclear variables $(n=1)$

Articles included for review $(n=27)$ 
Table 1

Summary information of the studies under review

\begin{tabular}{|c|c|c|c|c|c|c|}
\hline Study & Design & Sample Size\# & Sample Characteristics\# & Independent Variable(s) & Dependent Variable(s) & Quality* \\
\hline $\begin{array}{l}\text { Ang \& } \\
\text { Goh } \\
(2006)\end{array}$ & Correlational & 548 & $\begin{array}{l}\text { Gender (males): } 44.0 \% \\
\text { Age range: } 12-15 \text { years } \\
\text { Mean age: N/A } \\
\text { Ethnicity: N/A }\end{array}$ & Authoritarian & $\begin{array}{l}\text { Attitude towards } \\
\text { school/teachers } \\
\text { Self-esteem }\end{array}$ & $7(\mathrm{M})$ \\
\hline $\begin{array}{l}\text { Ang } \\
(2006)\end{array}$ & Correlational & 548 & 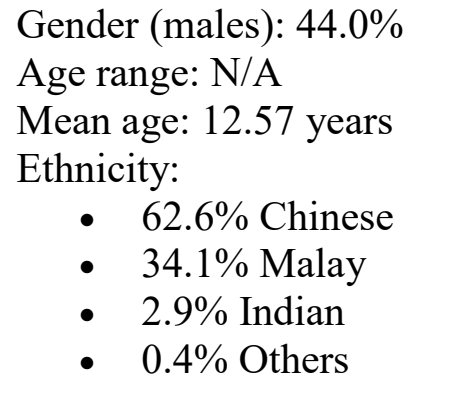 & $\begin{array}{l}\text { Authoritative } \\
\text { Authoritarian } \\
\text { Permissive }\end{array}$ & $\begin{array}{l}\text { Self-reliance } \\
\text { Interpersonal relations } \\
\text { Sense of inadequacy } \\
\text { Attitude to school } \\
\text { Self-esteem }\end{array}$ & $9(\mathrm{M})$ \\
\hline $\begin{array}{l}\text { Chen \& } \\
\text { Chng } \\
(2016)\end{array}$ & Longitudinal & 3079 & $\begin{array}{l}\text { Gender: N/A } \\
\text { Age range: } 8-17 \text { years } \\
\text { Mean age: } 12.98 \text { years } \\
\text { Ethnicity: N/A }\end{array}$ & $\begin{array}{l}\text { Active mediation } \\
\text { Restrictive mediation }\end{array}$ & $\begin{array}{l}\text { Self-regulation } \\
\text { Emotion regulation } \\
\text { Impulsivity }\end{array}$ & $8(\mathrm{M})$ \\
\hline $\begin{array}{l}\text { Cheung } \\
\& \\
\text { Elliott } \\
(2016)\end{array}$ & Correlational & 164 & $\begin{array}{l}\text { Gender (males): } 43.9 \% \\
\text { Age range: } 52-79 \text { months } \\
\text { Mean age: } 67.07 \text { months } \\
\text { Ethnicity: } \\
\text { - } 73.2 \% \text { Chinese } \\
\text { - } \quad 6.7 \% \text { Malay } \\
\text { - } 12.8 \% \text { Indian }\end{array}$ & $\begin{array}{l}\text { Maternal sensitivity } \\
\text { Structuring } \\
\text { Non-intrusiveness } \\
\text { Non-hostility }\end{array}$ & $\begin{array}{l}\text { Peer Likeability } \\
\text { Vocabulary } \\
\text { Nonverbal ability }\end{array}$ & $11(\mathrm{H})$ \\
\hline
\end{tabular}




Chew \& Correlational
Wang
(2008)
Chng et Correlational
al.
(2015)
Chong Correlational
\& Chan
(2015)

Choo \& Longitudinal Sim

(2015)
Gender (males): 54.2\% Age range: $14-20$ years

Mean age: N/A

Ethnicity: N/A

3079

Gender (males): 50.4\% Age range: 8 - 19 years

Mean age: 13.01 years Ethnicity: N/A

Gender (males): 50.8\% Age range: $12-17$ years Mean age: 13.94 years Ethnicity:

- $67 \%$ Chinese

- $27 \%$ Malay

- $3 \%$ Indian

- $3 \%$ Others

2974 Gender (males): $72.6 \%$ Age range: N/A

Mean age: 11.2 years Ethnicity:

- $72.6 \%$ Chinese

- $14.2 \%$ Malay

- $8.8 \%$ Indian

- $4.3 \%$ Others
Parental involvement

Parental autonomy-

support

Parental warmth

Active mediation

Restrictive mediation

Authoritative

Authoritarian

Permissive

Emotional intelligence

Self-talk

Self-perceptions

Aspirations

Pathological internet use

Closeness with child Restriction of child video-gaming

$6(\mathrm{M})$ 


\begin{tabular}{|c|c|c|c|c|c|c|}
\hline $\begin{array}{l}\text { Cui et } \\
\text { al. } \\
(2019)\end{array}$ & Correlational & 6237 & $\begin{array}{l}\text { Gender (males): } 50.6 \% \\
\text { Age range: N/A } \\
\text { Mean range: N/A }\left(4^{\text {th }}\right. \\
\text { graders) } \\
\text { Ethnicity: N/A }\end{array}$ & $\begin{array}{l}\text { Parental } \\
\text { involvement/attitude }\end{array}$ & $\begin{array}{l}\text { Learning interest in } \\
\text { mathematics } \\
\text { Mathematics achievement }\end{array}$ & $7(\mathrm{M})$ \\
\hline $\begin{array}{l}\text { Hong et } \\
\text { al. } \\
(2016)\end{array}$ & Longitudinal & 302 & 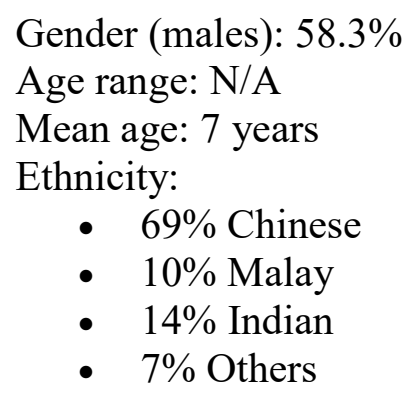 & $\begin{array}{l}\text { Parental intrusiveness } \\
\text { Positive support } \\
\text { Negative control }\end{array}$ & $\begin{array}{l}\text { Maladaptive perfectionism } \\
\text { Internalizing symptoms } \\
\text { Externalizing symptoms }\end{array}$ & $9(\mathrm{M})$ \\
\hline $\begin{array}{l}\text { Liau \& } \\
\text { Khoo } \\
(2005)\end{array}$ & Correlational & 1124 & $\begin{array}{l}\text { Gender (males): } 50.4 \% \\
\text { Age range: } 12-17 \text { years } \\
\text { Mean age: } 14.32 \text { years } \\
\text { Ethnicity: N/A }\end{array}$ & $\begin{array}{l}\text { Parental supervision } \\
\text { Parent-child } \\
\text { communication }\end{array}$ & Risky internet behaviour & $3(\mathrm{~L})$ \\
\hline $\begin{array}{l}\text { Liau et } \\
\text { al. } \\
(2008)\end{array}$ & Correlational & 169 & $\begin{array}{l}\text { Gender (males): } 64.5 \% \\
\text { Age range: } 12-16 \text { years } \\
\text { Mean age: } 13.91 \text { years } \\
\text { Ethnicity: N/A }\end{array}$ & $\begin{array}{l}\text { Parental supervision } \\
\text { Parental communication } \\
\text { Parental tracking }\end{array}$ & $\begin{array}{l}\text { Disclosure } \\
\text { Risky internet behaviour }\end{array}$ & $4(\mathrm{~L})$ \\
\hline
\end{tabular}




\begin{tabular}{|c|c|c|c|}
\hline $\begin{array}{l}\text { Liu \& } \\
\text { Ang } \\
(2013)\end{array}$ & Correlational & 780 & $\begin{array}{l}\text { Gender (males): } 49.1 \% \\
\text { Age range: } 13-18 \text { years } \\
\text { Mean age: } 13.94 \text { years } \\
\text { Ethnicity: } \\
\text { - } 74.6 \% \text { Chinese } \\
\text { - } 19.7 \% \text { Malay } \\
\text { - } 2.6 \% \text { Indian } \\
\text { - } 0.4 \% \text { Caucasian } \\
\text { - } 2.4 \% \text { Others }\end{array}$ \\
\hline $\begin{array}{l}\text { Liu et } \\
\text { al. } \\
(2016)\end{array}$ & Correlational & 780 & $\begin{array}{l}\text { Gender (males): } 49.1 \% \\
\text { Age range: } 13-18 \text { years } \\
\text { Mean age: } 13.94 \text { years } \\
\text { Ethnicity: } \\
\text { - } 74.6 \% \text { Chinese } \\
\text { - } 19.7 \% \text { Malay } \\
\text { - } 2.6 \% \text { Indian } \\
\text { - } 2.8 \% \text { Others }\end{array}$ \\
\hline $\begin{array}{l}\text { Luo \& } \\
\text { Aye } \\
(2013)\end{array}$ & Correlational & 1667 & $\begin{array}{l}\text { Gender (males): } 52.7 \% \\
\text { Age range: N/A } \\
\text { Mean age: } 14.93 \text { years } \\
\text { Ethnicity: } \\
\text { - } 73.3 \% \text { Chinese } \\
\text { - } \quad 14.6 \% \text { Malay } \\
\text { - } 7.1 \% \text { Indian } \\
\text { - } \quad 5.0 \% \text { Others }\end{array}$ \\
\hline
\end{tabular}

Active mediation

Restrictive mediation

Parental mediation

Personal information disclosure

Disclosure of personally identifiable information Concern for privacy

Parental involvement Parental control

Performance/mastery goals School-related engagement Self-regulation Math self-concept Math anxiety

Math achievement 


\begin{abstract}
Luo et Longitudinal
\end{abstract}
al.

(2016)

Ong \& Longitudinal

Eilander

(2018)

Pang \& Longitudinal

Ang

(2013)
2648

Gender (males): 36.5\%

Age range: N/A

Mean age: 13.78 years

Ethnicity:

- $67.6 \%$ Chinese

- $18.1 \%$ Malay

- $7.1 \%$ Indian

- $7.2 \%$ Others

445

Gender (males): $43.2 \%$ Age range: 6-10 years

Mean age: 7.8 years

Ethnicity:

- $78.0 \%$ Chinese

- $14.6 \%$ Malay

- $6.7 \%$ Indian

- $0.4 \%$ Others

1148

Gender (males): 52.5\%

Age range: N/A

Mean age: 13.17 years

Ethnicity:

- $67.0 \%$ Chinese

- $21.0 \%$ Malay

- $8.1 \%$ Indian

- $3.9 \%$ Others
Parental expectancy

Parental involvement

Parenting care

Overprotection/control
Math self-efficacy, value,

enjoyment, pride, boredom,

and anxiety

Homework effort

Homework distraction

Internalising and

externalising symptoms
5 (M)

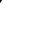

\section{Authoritative \\ Authoritarian \\ Permissive}

Aggression

Behavioural and emotional

adjustment

Delinquency 


\begin{tabular}{|c|c|c|c|c|c|c|}
\hline $\begin{array}{l}\text { Sha \& } \\
\text { Looi } \\
(2012)\end{array}$ & Correlational & 67 & $\begin{array}{l}\text { Gender (males): } 56.7 \% \\
\text { Age range: N/A } \\
\text { Mean age: N/A }\left(4^{\text {th }}\right. \\
\text { graders) } \\
\text { Ethnicity: N/A }\end{array}$ & $\begin{array}{l}\text { Parental autonomy- } \\
\text { support }\end{array}$ & $\begin{array}{l}\text { Self-regulated learning } \\
\text { Learning achievement }\end{array}$ & $7(\mathrm{M})$ \\
\hline $\begin{array}{l}\text { Shin \& } \\
\text { Kang } \\
(2016)\end{array}$ & Correlational & 746 & $\begin{array}{l}\text { Gender (males): } 52.0 \% \\
\text { Age range: } 12-18 \text { years } \\
\text { Mean age: } 14.3 \text { years } \\
\text { Ethnicity: N/A }\end{array}$ & $\begin{array}{l}\text { Instructive mediation } \\
\text { Restrictive mediation }\end{array}$ & $\begin{array}{l}\text { Online privacy concerns } \\
\text { Online information } \\
\text { disclosure } \\
\text { Willingness to disclose } \\
\text { personal information }\end{array}$ & $6(\mathrm{M})$ \\
\hline $\begin{array}{l}\text { Shin \& } \\
\text { Lwin } \\
(2017)\end{array}$ & Correlational & 746 & $\begin{array}{l}\text { Gender (males): } 52.0 \% \\
\text { Age range: } 12-18 \text { years } \\
\text { Mean age: } 14.3 \text { years } \\
\text { Ethnicity: N/A }\end{array}$ & Active mediation & $\begin{array}{l}\text { Online risk-taking } \\
\text { behaviour }\end{array}$ & $3(\mathrm{~L})$ \\
\hline $\begin{array}{l}\text { Shin et } \\
\text { al. } \\
(2020)\end{array}$ & Correlational & 603 & 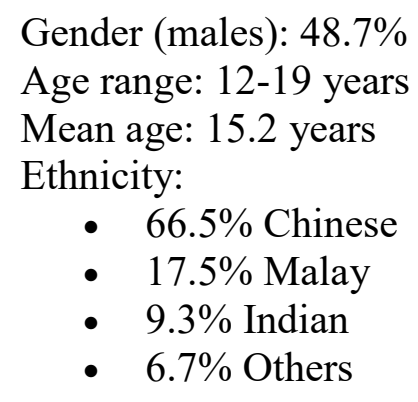 & Parental mediation & $\begin{array}{l}\text { Attitudes towards in-app } \\
\text { display advertising } \\
\text { Attitudes towards personal } \\
\text { information collection by } \\
\text { apps } \\
\text { In-app display advertising } \\
\text { avoidance }\end{array}$ & $7(\mathrm{M})$ \\
\hline $\begin{array}{l}\text { Sim \& } \\
\text { Singh } \\
(1991)\end{array}$ & Correlational & 50 & $\begin{array}{l}\text { Gender (males): } 100 \% \\
\text { Age range: N/A } \\
\text { Mean age: N/A }\left(6^{\text {th }}\right. \\
\text { graders) } \\
\text { Ethnicity: N/A }\end{array}$ & $\begin{array}{l}\text { Child-rearing attitudes/ } \\
\text { practices }\end{array}$ & Conduct problems & $2(\mathrm{~L})$ \\
\hline
\end{tabular}




\begin{tabular}{|c|c|c|c|c|c|c|}
\hline $\begin{array}{l}\text { Sim } \\
(2000)\end{array}$ & Correlational & 555 & $\begin{array}{l}\text { Gender (males): } 53.5 \% \\
\text { Age range: } 12-16 \\
\text { Mean age: N/A } \\
\text { Ethnicity: } \\
\text { - } 91 \% \text { Chinese } \\
\text { - } 3 \% \text { Malay } \\
\text { - } 1 \% \text { Indian }\end{array}$ & $\begin{array}{l}\text { Parental support } \\
\text { Parental monitoring }\end{array}$ & $\begin{array}{l}\text { Regard for parents } \\
\text { Self-esteem } \\
\text { Antisocial susceptibility }\end{array}$ & $5(\mathrm{M})$ \\
\hline $\begin{array}{l}\text { Sim \& } \\
\text { Ong } \\
(2005)\end{array}$ & Correlational & 286 & $\begin{array}{l}\text { Gender (males): } 50.0 \% \\
\text { Age range: } 4-6 \text { years } \\
\text { Mean age: N/A } \\
\text { Ethnicity: } 100 \% \text { Chinese }\end{array}$ & $\begin{array}{l}\text { Authoritative control } \\
\text { Parental rejection } \\
\text { Physical punishment }\end{array}$ & Aggression & $5(\mathrm{M})$ \\
\hline $\begin{array}{l}\text { Sim \& } \\
\text { Chin } \\
(2014)\end{array}$ & Correlational & 284 & $\begin{array}{l}\text { Gender (males): } 45.0 \% \\
\text { Age range: N/A } \\
\text { Mean age: } 13.5 \text { years } \\
\text { Ethnicity: } 62 \% \text { Chinese } \\
\text { (others not reported) }\end{array}$ & $\begin{array}{l}\text { Authoritative } \\
\text { Authoritarian }\end{array}$ & $\begin{array}{l}\text { Academic ability } \\
\text { Academic self-esteem } \\
\text { Interest in school } \\
\text { Achievement goals }\end{array}$ & $6(\mathrm{M})$ \\
\hline $\begin{array}{l}\text { Stright } \\
\text { \& Yeo } \\
(2014)\end{array}$ & Correlational & 712 & $\begin{array}{l}\text { Gender (males): } 47.9 \% \\
\text { Age range: } 9-12 \text { years } \\
\text { Mean age: N/A } \\
\text { Ethnicity: } \\
\text { - } 74.0 \% \text { Chinese } \\
\text { - } 16.4 \% \text { Malay } \\
\text { - } 7.3 \% \text { Indian } \\
\text { - } 2.2 \% \text { Other }\end{array}$ & $\begin{array}{l}\text { Parental Warmth } \\
\text { Psychological control } \\
\text { Behavioural control } \\
\text { School involvement }\end{array}$ & $\begin{array}{l}\text { Academic achievement } \\
\text { School conduct }\end{array}$ & $7(\mathrm{M})$ \\
\hline
\end{tabular}

Note. ${ }^{~}$ For longitudinal studies, sample size and characteristics at Time 1 are listed. ${ }^{*}$ A numeric score for study quality is listed. $\mathrm{H}=\mathrm{High}$ quality; $\mathrm{M}=$ Medium; $\mathrm{L}=$ Low. 


\section{Results}

Table 1 summarises information on the 27 reviewed studies. The majority of the studies (21) had a correlational design, while six were longitudinal. Most of the studies focused on the adolescence phase (19 studies), and had children as the only informants (21 studies). Five studies included the perspectives of both parents and children. As shown in Table 1, this review found that local parenting research consists of a good mix of studies that looked into the intrapersonal, interpersonal, behavioural and academic outcomes of children, encompassing a rather holistic view of development despite the importance of academic achievement in Singapore. Upon close scrutiny, most of the parenting constructs could be organised according to the dimensions of demandingness or control, and responsiveness or warmth. This system of organisation is in line with the widely-endorsed conceptualisations where parenting behaviours are cast in terms of varying degrees of demandingness and responsiveness (Baumrind, 1966; Maccoby \& Martin, 1983), as well as parental warmth and control (Rohner et al., 2005).

A total of 20 out of 27 studies in this review reported findings on at least one of these dimensions, while the remaining seven studies looked at various types of parental involvement in the education context, such as providing children with homework help (e.g., Luo et al., 2016) or attending school events (e.g., Stright \& Yeo, 2014). However, parental involvement does not align well with the broad dimensions of control and warmth. It usually relates to parental behaviours in support of a child's academic endeavours that can be quite independent of control and warmth. Conceptually, parental involvement is also less susceptible to different cultural interpretations, unlike parental control and warmth where their forms and functions are more likely to change across contexts (Bornstein, 2015). Hence, this review will focus on analysing and discussing findings based on parenting constructs with direct links to the dimensions of demandingness/control and responsiveness/warmth. 
Following this system of organisation, the selected constructs for discussion are parental authoritativeness (five studies), authoritarianism (five studies), permissiveness (three studies) and warmth (three studies), which fall under parenting styles. Studies related to parenting practices include parental control (three studies) and parental mediation in the context of children's media use (nine studies).

\section{Parenting Styles}

Building upon Baumrind's (1966) earlier work on conceptualising parenting styles that combined emotional and behavioural processes, Maccoby and Martin (1983) developed a framework for organising parenting styles along two orthogonal dimensions of demandingness and responsiveness. Demandingness represents parents' use of control strategies in their attempts to socialise the child by demanding behavioural compliance (Darling \& Steinberg, 1993), while responsiveness refers to parents' recognition of the child's individuality by being attuned to their needs (Baumrind, 1966). Based on these two dimensions, a parent could be classified as authoritative (high demandingness and high responsiveness), authoritarian (high demandingness and low responsiveness), permissive/indulgent (low demandingness and high responsiveness), or neglectful (low demandingness and low responsiveness). Some researchers have asserted that the authoritative and authoritarian styles should be advocated as the epitome of optimal and suboptimal parenting respectively (Steinberg, 2001). However, other studies have shown that the functional value of specific practices and styles may differ in an Asian context compared to the Western context (Chao, 1994). This suggests that the parenting style typology may not be universally generalisable where associations with child development outcomes are concerned. Overall, findings from the Singaporean studies support the view of a more culturally nuanced interpretation of parenting styles. In this section, findings from authoritative, authoritarian and permissive parenting are discussed, along with those related to parental warmth. Warmth 
is considered to be a parenting style as it represents the emotional climate within the parentchild relationship, mapping directly onto Darling and Steinberg's (1993) definition.

\section{Authoritative Style}

Five studies examined the associations between authoritative parenting and children's interpersonal (e.g., social skills), intrapersonal (e.g., self-esteem), behavioural (e.g., aggression), and academic outcomes (e.g., academic ability). In all of these studies, authoritative parenting was measured using the Parental Authority Questionnaire (PAQ; Buri, 1991), making the concept comparable across studies. Overall, the results showed that authoritative parenting has a positive connotation in the Singaporean context, just like in most other Asian and Western societies (Pinquart \& Kauser, 2018), being related to desirable outcomes in all of the above-mentioned aspects of development. In particular, authoritative parenting appears to deliver the most apparent benefits to the intra- and interpersonal development of children in Singapore, more so than behavioural and academic outcomes.

In terms of intrapersonal development, paternal and maternal authoritativeness was related to higher self-esteem, greater self-reliance and a lower sense of inadequacy (Ang, 2006). Authoritativeness also predicted adolescents' enhanced ability to manage their emotions, and to use emotions in a positive way (Chong \& Chan, 2015). In terms of interpersonal outcomes, paternal and maternal authoritativeness was related to better interpersonal relationships (Ang, 2006), having good social skills and being aware of others' emotions (Chong \& Chan, 2015). For behavioural outcomes, parental authoritativeness was related to less likelihood of children exhibiting maladaptive behaviours, such as aggression, anxious/depressed and withdrawn/depressed symptoms, and fewer delinquent behaviours, but the effect sizes were very small ( $r$ s from -.06 to -.13 ).

Although authoritative parenting generally predicted positive behavioural outcomes, there were notable exceptions too. Adopting the person-centred approach, Pang et al. (2013) 
found that adolescents with varying levels of proactive and reactive aggression did not differ on the amount of authoritative parenting they received. Similarly, authoritative parenting was not related to teacher-rated child aggression, contrary to expectation (Sim \& Ong, 2005).

Like studies on children of Asian descent, authoritative parenting was not directly related to academic performance in Singapore, although only one study had examined this association. Nonetheless, authoritative parenting does seem to have the potential to contribute indirectly to academic outcomes through changing the attitudes of adolescents towards school and learning. For example, Sim and Chin (2014) found that authoritative parenting was not related to adolescents' self-perceived academic ability relative to other students. However, it was related to greater interest in school and enhanced mastery and performance approach goals, where mastery and performance goals relate to the attainment of competence based on intrapersonal standards (mastery) and competence in comparison to peers (performance). Authoritative parenting was also related to adolescents holding a better attitude towards school (Ang, 2006).

Interestingly, Singaporean studies on authoritative parenting also painted a more nuanced picture, especially when the genders of parents and children were considered. Sim and Chin (2014) showed that paternal and maternal parenting styles interact statistically in relation to children's development. For example, paternal authoritativeness was related to adolescents' better self-perceived grades, but only when maternal authoritativeness was low. Similarly, paternal authoritativeness was related to better self-perceived grades only when mothers displayed a high level of authoritarian parenting. These results suggest that paternal authoritativeness in particular seems to have a compensatory effect in instances where maternal authoritativeness was low. Importantly, studies like this underscore the fact that behaviours from parents and caregivers work in combination in influencing children's behaviour in a dynamic manner, in line with systems theory (Guttman, 1991). Yet, the 
majority of the studies in the current review had only examined the correlates of the practices and styles of one parent, usually the mother.

\section{Authoritarian Style}

Unlike authoritative parenting, where it was almost always related to more desirable child development outcomes, findings on the correlates of authoritarian parenting were more mixed. In all, five studies reported findings linking authoritarian parenting to outcomes in the intrapersonal, behavioural and academic domains. Similar to studies conducted in Western contexts, authoritarian parenting seems to adversely affect children's self-concept. For example, maternal and paternal authoritarianism was related to lower self-esteem and a greater sense of inadequacy (Ang, 2006), as well as greater negative self-talk among adolescents (Chong \& Chan, 2015). Authoritarian parenting was also positively associated with undesirable behaviours and adjustment problems among adolescents, namely reactive aggression, proactive aggression, aggressive behaviour, rule-breaking, attentional problems, anxious/depressed and withdrawn/depressed symptoms, somatic complaints and delinquency (Pang \& Ang, 2013). In the academic context, Sim and Chin (2014) found that authoritarian parenting was linked to greater performance avoidance goals, suggesting that adolescents with authoritarian parents tended to avoid failing in front of others. This may stem from a past history of parental harshness when children had failed, especially when the failure was publicly known which resulted in the parents "losing face", or feeling ashamed (Chao, 2001).

Interestingly, despite the evidence demonstrating the possible negative effects of authoritarian parenting, results also showed that authoritarianism was not universally linked to poorer child development outcomes. This is consistent with research conducted in other non-Western contexts, where authoritarianism was either not associated with any adverse psychological outcomes among Arabic adolescents (Dwairy, 2008) or was positively associated with academic achievement among adolescents in Hong Kong (Leung et al., 
1998). In the Singaporean context, Pang and Ang (2013) found no difference in adolescents' level of aggressiveness as a function of their parents' level of authoritarianism. Ang (2006) further reported that Singaporean Malay adolescents with authoritarian mothers did not differ in their attitudes towards school compared to those with authoritative mothers, suggesting that authoritarianism may have a limited impact on children's academic outcomes (c.f., Leung et al., 1998). Similar to the study by Li et al. (2010) which reported a positive association between authoritarian parenting and socioemotional adjustment in China, Chong and Chan (2015) found that Singaporean adolescents with authoritarian mothers tended to have better self-management of emotions. This is likely because the highly controlling nature of authoritarian parenting serves to inhibit emotional expressions among adolescents, where emotional restraint is a valued characteristic that is practised and encouraged in the Singaporean context (Hurley et al., 2016).

Similar to what was observed for authoritative parenting, the current findings on authoritarian parenting revealed clear differences in maternal and paternal parenting. Using cluster analysis, Ang and Goh (2006) found that among adolescents with authoritarian mothers, more were classified as well-adjusted $(\mathrm{N}=171)$ than maladjusted $(\mathrm{N}=117)$. However, for adolescents with authoritarian fathers, more were considered to be maladjusted $(\mathrm{N}=167)$ than well-adjusted $(\mathrm{N}=94)$. Based on these findings, maternal authoritarianism seems to have a more positive connotation in this cultural context than paternal authoritarianism. One possible explanation for this is that in Singapore, mothers tend to be the main caregivers for children (Cheung \& Hawkins, 2014). In a way, authoritarian mothering, as exemplified by a high degree of control with little room for negotiation, may have been interpreted favourably as care and concern, or at least as an act that is normative without any negative implication. This finding is interesting as it goes against the popular notion of fathers being the strict disciplinarian in Asian households, while mothers assume 
the role of a nurturer (Chao \& Tseng, 2002). In fact, it seems that strict fathering is not linked to developmental advantages in Singapore, even as paternal authoritarianism appears to be culturally normative based on Asian parenting and patriarchal values. However, a caveat is that we do not actually have strong evidence suggesting that Singaporean fathers are necessarily stricter than mothers as was observed in other Asian contexts (Chao \& Tseng, 2002), in view of a paucity of research on fathering in Singapore.

\section{Permissive Style}

Parental permissiveness is seldom examined in the local context, likely because permissive and neglectful parenting is particularly rare in Asian families, where constant monitoring of children is a hallmark of good and responsible parenting (Chao \& Tseng, 2002). Moreover, Asian parents tend to be motivated to closely monitor their children because children are seen as an extension of parents, where children's success is intertwined with parents' personal identities and self-worth ( $\mathrm{Ng}$ et al., 2014). Therefore, even though researchers might have collected data on permissive parenting in their studies, the infrequent occurrence of such practices, as was also observed in other Asian contexts such as China (Zhang et al., 2017), may present challenges for any meaningful comparisons to be made. In this review, only three studies presented results on permissive parenting.

Although Western and Asian parenting literature point to the detrimental effect of permissive parenting, such as an increase in delinquent behaviours among children (Hoeve et al., 2009), the findings on permissive parenting were quite mixed in Singapore. This pattern of results concurred with those reported by Steinberg et al. (1994), where a sample of ethnically-diverse American adolescents who had permissive parents tended to do better in terms of somatic symptoms and academic self-concept over the course of one year, but also experienced declines in school orientation and an increase in delinquent behaviour over time. Pertaining to the negative correlates of permissiveness in Singapore, it was linked to 
poorer attitudes towards school (Ang, 2006) and greater levels of child aggression (Pang \& Ang, 2013) among adolescents. Presumably, the lack of guidance and structure in permissive parenting likely exposes children to more deviant peer groups, and allows adolescents to engage in aggressive acts freely without clear negative consequences (Pang \& Ang, 2013).

On the other hand, permissiveness was also linked to better emotional development among children. Chong and Chan (2015) found that parents' permissiveness was related to adolescents' more positive use of emotions; while maternal permissiveness was related to better social skills and paternal permissiveness to adolescents' greater awareness of others' emotions. Parental permissiveness has likely facilitated good social and emotional development because children may have modeled after their parents' high level of responsiveness, as is characteristic of permissive parenting, which in turn benefitted children's social skills development. The low levels of parental control or demandingness may also have encouraged the free expression of emotions.

\section{Parental Warmth}

Parental warmth is the expression of a parents' acceptance and rejection, often conveyed through parenting behaviours such as responsiveness, appropriate monitoring and positive affective communication (Khaleque, 2013; Ying et al., 2019). Warmth is also a crucial dimension that underpins the Parental Acceptance-Rejection Theory (PARTheory; Rohner et al., 2005), where its expression through physical (e.g., hugs and kisses) and/or verbal forms (e.g., praises) convey a sense of acceptance, resulting in psychological maladjustment in children in instances where parental acceptance is not received or perceived. Cross-cultural research on PARTheory has shown that the notion of parental acceptance transcends cultural boundaries, even as there exist cultural variations in its expression (Rohner et al., 2005). 
Given the fundamental role of parental warmth in child socialisation as postulated by PARTheory, it is surprising that only three studies had focused on parental warmth and its association with children's development in Singapore. One of the three studies (Ong et al., 2018) was excluded from this narrative discussion because parental warmth was combined with control to form a separate construct labelled as "optimal care" in the analysis, compromising conceptual clarity. As expected, parental warmth was related to the psychological well-being of adolescents (age 14 to 20), being associated with increased general self-worth, greater intrinsic aspirations and less amotivation (Chew \& Wang, 2008). However, parental warmth was not associated with adolescents' academic grades and conduct in school as rated by teachers (Stright \& Yeo, 2014). This is similar to the study by Chen et al. (2000), who found that maternal warmth only predicted emotional adjustment but not academic achievement in China. On the other hand, paternal warmth was related to subsequent social and school achievement. Because none of the Singaporean studies examined paternal warmth, it is not known if similar effects would have been found in the local context.

Despite the absence of an association between parental warmth and school outcomes, parental warmth did serve as an important context within which parenting practices are interpreted. As Stright and Yeo (2014) have shown, mothers' school-based involvement predicted better academic achievement among adolescents, but only if the involvement cooccurred with a high level of maternal warmth. No such moderating effect was observed at mean or low levels of maternal warmth. This result shows that in the context of a warm mother-child relationship, children perceive their mothers' involvement as an act of love and acceptance, whereas the same behaviour is likely interpreted as an act of intrusion in a lowwarmth environment. 


\section{Parenting Practices}

Parenting practices, or parenting behaviours that contribute to the socialisation of the child, can take various forms. Of the 27 studies in this review, 21 examined at least one parenting practice, most commonly related to the control dimension (e.g., psychological and behavioural control and parental mediation). Overall, findings from the Singaporean literature concur with the view about the need to differentiate the types of control, in view of variations in their emotional meanings.

\section{Control}

Parental control is often distinguished by two forms - behavioural control and psychological control. Both serve the common function of controlling children's behaviour, but carry very different interpretative meanings. According to Aunola and Nurmi (2005), behavioural control is the regulation of children's behaviour through rules, rewards and discipline; while psychological control is defined as controlling children's emotions and behaviour by psychological manipulation of the parent-child relationship. Behavioural control is regarded desirably due to its goals of teaching children the necessary socialisation and social interaction skills. Expectedly, it is associated with better self-regulation and fewer behavioural problems among children (Aunola \& Nurmi, 2005). Conversely, psychological control is seen as less optimal because of its intrusive and hostile underpinning that undermines the psychological autonomy a child needs to develop their identity (Barber et al., 1994; Bornstein, 2015). Conceivably, psychological control was linked to negative child outcomes such as behavioural problems and poorer mental health (Aunola \& Nurmi, 2005; Barber et al., 2005).

The current review found three studies that examined relations between controlrelated constructs and children's academic achievement and school conduct. The results show that behavioural control was linked to good child development outcomes. Although 
psychological control tended to be linked to poorer child development, it was not invariably undesirable. For example, Stright and Yeo (2014) found that behavioural control was associated with children's better academic achievement, while the reverse was true for psychological control. This is in line with findings reported by Wang et al. (2007), where parental behavioural control predicted children's enhanced academic functioning in both the United States and China. The local findings also concur with those based on a meta-analysis of studies on parenting styles and children's academic achievement, where psychological control was related longitudinally to worse academic achievement in both Western and nonWestern contexts (Pinquart, 2016).

Although behavioural control has been positively linked to children's psychosocial functioning, and psychological control to behavioural problems (Aunola \& Nurmi, 2005; Barber et al., 2005), Stright and Yeo (2014) found that neither form of maternal control predicted children's conduct in school. The authors speculated that the null findings may be attributed to a ceiling effect for the measure of school conduct, which was obtained from school records and based on teachers' assessment of the child's day-to-day conduct at school.

Interestingly, both behavioural and psychological control had positive associations with maternal warmth (Stright \& Yeo, 2014). Contrary to expectation, this shows that psychological control also conveyed a degree of acceptance towards the child in a way behavioural control did, implying that psychological control may have some positive connotation in the Singaporean context.

Two other studies focused on parental control in relation to children's behavioural and school outcomes, but interpretations of those findings were less straightforward because the authors did not make a distinction between behavioural and psychological control in their operationalisation. Hong et al. (2016) found that parental negative control (measured by parental discipline, harsh punishment, and ignoring) was significantly correlated with 
children's internalising and externalising symptoms. Note that the concept of negative control overlaps somewhat with the concept of psychological control in that study. In another study, Luo et al. (2013) included items representing both behavioural and psychological control in their measure of "parental control", and found that control was related to adolescents" poorer math achievement, greater math anxiety and poorer effort regulation. The inclusion of items related to coercive discipline in Luo et al. (2013) may have accorded the construct of parental control a negative meaning in that study, which highlights the importance of distinguishing items of parental control related to coercion versus structuring.

\section{Mediation}

Parental mediation is a form of control exercised specifically in the context of media use among children and adolescents. Parental mediation strategies aim to protect children from the negative effects of technology, such as invasion of privacy and safety (Lwin et al., 2008), while allowing them to attain media literacy (Livingstone \& Helsper, 2008). Local studies focused on two forms of mediation - active and restrictive. According to Jiow et al. (2017), active or instructive mediation refers to pro-active parental communication with children regarding media use (e.g., discussing safe internet practices); while restrictive mediation refers to parental rules surrounding media use (e.g., limiting time spent on video games).

In line with self-determination theory (Ryan \& Deci, 2000), past research has shown active mediation to be more effective than restrictive mediation in ensuring adolescents's safe Internet use (Shin \& Kang, 2016). This is because in active mediation, parents' collaborative discussions convey a sense of respect for adolescents' autonomy. This makes it more likely for them to internalise these practices and comply with parents' expectations on their own accord. On the other hand, the imposition of rigid rules in restrictive mediation infringes upon adolescents' need for autonomy, resulting in greater reactance (Shin \& Kang, 2016). 
The present review yielded nine studies that examined parents' active and restrictive mediation, but with mixed results. On the one hand, active mediation was related to desirable outcomes; but on the other, restrictive mediation was related to both positive and negative outcomes. Shin and Kang (2016) found that adolescents whose parents used active mediation were less willing to disclose personal identifiable information to acquaintances online. They were also less likely to actually disclose such information, which concurred with findings by Liu et al. (2013). This supports the self-determination theory as outlined earlier, where parental discussion aids the internalisation of beliefs and values that serve to reinforce adolescents' awareness of privacy needs.

Concurring with previous research on the negative effects of restrictive mediation, Shin and Kang (2016) found that restrictive parental mediation predicted greater disclosure of personally identifiable information by adolescents. Despite this, however, three other studies reported positive outcomes of restrictive mediation. For example, Liu et al. (2013) found that restrictive mediation reduced the likelihood of information disclosure through increasing adolescents' concern for privacy. In this case, having strict rules about Internet use had in fact solidified adolescents' beliefs on the importance of privacy. Similarly, Chng et al. (2015) found that adolescents whose parents practised restrictive mediation were less likely to become pathological Internet users. Importantly, these benefits were enhanced when adolescents experienced a warm family climate.

Other studies also found evidence of the effectiveness of both active and restriction mediation. Liau et al. (2005) and Liu et al. (2013) showed that both forms of mediation lowered the risks of adolescents meeting their online acquaintances face-to-face and disclosing personally identifiable information. Additionally, Liu et al. (2016) reported that the combined construct of active and restrictive mediation decreased adolescents' willingness and actual disclosure of personal information on Facebook. The fact that both active and 
reactive mediation are effective reflect a reality that likely exists in most families, where parents use a combination of methods depending on their goals (immediate compliance or longer-term self-regulation abilities) and the age of the child. In a longitudinal study, Chen and Chng (2016) found that active and restrictive mediation predicted adolescents' greater online self-regulation and emotion regulation, and less impulsivity two years later. A slower decrease in both types of mediation was linked to better online self-regulation and lower impulsivity over time, suggesting that children benefit from some level of continued control. Interestingly, parents who used more active mediation at Time 1 (age 8-17) used less restrictive mediation over time. Hence, the adoption of active mediation earlier on may have been an effective long-term control strategy, such that fewer rules were required with time. It also shows the evolution of parental strategies that are likely sensitive to children's developmental needs, where parents curtail their restrictive control in response to children's better self-regulation ability as they mature, and their increased needs for autonomy. In short, these findings imply that although active mediation seems to be an effective long-term strategy in protecting children from the harms of technology, restrictive mediation is also effective, especially when children are younger.

\section{Discussion}

This systematic review was undertaken with the main goal of identifying parenting styles and practices that have been examined in research in Singapore, and their associations with a diverse array of child developmental outcomes. Another goal was to compare the correlates of parenting styles and practices in Singapore with those observed in other Asian and Western societies, in order to identify patterns in the generality and specificity of forms and functions of parenting behaviours. While it was not feasible to review and discuss all of the available studies conducted in other Asian and Western societies as a basis for comparing with Singaporean data, the current study revealed a coherent pattern of findings with clear 
research and practice implications. Foremost, the current review shows that there are some indicators of "good" parenting, as are also observed in other cultural contexts, which we may encourage local parents to adopt. These include authoritative parenting, parental warmth, behavioural control and active mediation. However, this review also shows that parenting styles and practices that are widely considered to be sub-optimal in many cultures may not invariably translate into undesirable outcomes for children in Singapore. Examples of these are authoritarian and permissive parenting, psychological control, and restrictive mediation. Contextual factors need to be taken into account when considering the functional value of parenting behaviours.

According to Steinberg (2001), authoritative parenting is an effective form of parenting that should be advocated for use globally. This is because the high degree of parental involvement and structuring provide good support for children's ongoing development of self-regulation, while the nurturance and verbal give-and-take create a warm emotional climate that enhances the effectiveness of parenting behaviours. Hence, the characteristics of authoritative parenting seem to align well with the key principles of effective socialisation, where the child is respected as a key partner in the socialisation process. On the effects of authoritarian parenting, Steinberg (2001) further asserted that the negative impact of authoritarianism transcends cultural boundaries. Whereas the literature shows that children of Asian descent are not as negatively affected by authoritarianism as European American adolescents are, it is distinct from arguing that Asian children benefit from authoritarian parenting. Overall, results of this review concurred with Steinberg's (2001) view on the effects of authoritative and authoritarian parenting. The advantages of authoritative parenting are evident through its associations with better intrapersonal, interpersonal and behavioural outcomes among children in Singapore. Although Singaporean children with authoritarian parents tended to have poorer intrapersonal and behavioural 
outcomes, it has no observable impact either way on children's emotional and academic outcomes. In fact, regarding emotional development, authoritarianism was linked to adolescents' better self-management of emotions (Chong \& Chan, 2015), suggesting that authoritarianism may have some (though limited) positive connotation in this cultural context.

The finding that authoritarian parenting may bring about some benefits for Singaporean children aligns with Chao's (1994) work, where she stated that the concept of authoritarianism does not fully represent the gist of parental control in Asian families. According to Chao (1994), Asian (Chinese) parents prioritise training (the concept of guan) their children through strict monitoring and control in ways that are similar to the high degree of control authoritarian parents exercise. However, training is fundamentally performed out of love and concern for the child, entailing a fair degree of parental effort and sacrifice so as to secure the best possible outcome for the child. Interestingly, Asian children also interpreted these strict and controlling behaviours favourably, which translated into developmental benefits despite a presumed infringement of the child's autonomy (Stewart et al., 2002). Separately, in accounting for the lack of an association between authoritarian parenting and Indonesian adolescents' life satisfaction and mental health indices, Abubakar et al. (2015) contended that in cultures that emphasise group harmony rather than personal autonomy, as is the case for Indonesia, strict parenting may be valued because respect for authority and hierarchy is crucial for maintaining social cohesion. In all, these cultural factors may account for why authoritarian parenting does not have a clear negative connotation in Singapore.

Interestingly, the review on parental practices unveiled many similarities with the patterns of findings observed in parenting styles. The types of control that are viewed favourably in Western contexts (i.e., behavioural control, active mediation) were also 
positively associated with children's development in Singapore. On the other hand, "negative" control such as psychological control and restrictive mediation had both positive and negative overtones in Singapore, similar to authoritarian parenting. One possible explanation may lie in the emotional meaning and intentions underpinning those control practices. For example, behavioural control and active mediation both involve components of negotiation and reasoning that position child socialisation as a collaborative process, one which enhances its effectiveness, similar to the benefits seen in authoritative parenting. On the other hand, psychological control and restrictive mediation both constitute unilateral power assertion, where parents yield full control over their children in ways similar to an authoritarian style. Theoretically, this latter form of control should be less effective, as they compromise the child's need for autonomy. However, the finding that psychological control co-occurred with parental warmth even from the perspective of children in Singapore (Stright \& Yeo, 2014), and that restrictive mediation was linked to adolescents' safe Internet use demonstrate that some degree of power assertion and dominance may not be counterproductive. This may be possible if children live in cultural contexts that emphasise respect for parental authority, such as in Singapore (Cheung \& Sim, 2017), and understand the intentions behind parental control. Overall, optimal parenting in Singapore does resemble optimal parenting in Western contexts, but children are at the same time protected somewhat from the "detrimental" effects of strict parenting and control, if the well-intentioned meaning behind those parenting behaviours are conveyed. This mixed pattern is perhaps to be expected in view of the strong Western influence on the beliefs and ideals of Singaporean families, but also in light of the equally strong Asian heritage where parental authority is accepted and respected. 


\section{Recommendations for Research and Practice}

This systematic review of parenting styles and practices in Singapore has brought to light the cultural meaning of parenting styles and practices in relation to the core dimensions of control/demandingness and warmth/responsiveness. Several insights on the functional value of styles and practices were gleaned, including how their correlates are similar to or different than those observed in other Asian and Western contexts. Although this review has only included studies conducted in a single society which limits its generalisability to other contexts with a different demography, it was crucial to use a single Asian society as a starting point. Keeping the scope of the review focused has enabled us to identify areas of generality and specificity in a vastly understudied culture, which adds to a nuanced understanding of Asian parenting. The existing literature on Asian parenting has focused predominantly on immigrant samples in North America, but the process and context of immigration may influence parenting in ways that are not seen among Asian families living in their cultures of origin. Future reviews could focus on another Asian context with which comparisons could be made to other societies in and outside of Asia.

The current analysis of parenting constructs related to control and warmth has posed further questions on the specificity of the constructs. For example, the finding that "negative" control may confer some benefits to Singaporean children's development gives rise to questions pertaining to which components of control contribute to adaptive functioning. Furthermore, few studies have looked at the concept of parental warmth in Singapore, where emotional restraint and suppression is practised and encouraged (Hurley et al., 2016). It remains to be known whether the concept of warmth needs to be further expanded to include examples of instrumental aid beyond overt physical and emotional expressions of love (e.g., Cheah et al., 2015). A qualitative analysis or naturalistic observations using an emic approach would best address questions of this nature, where parents and children describe or 
demonstrate instances of control and warmth across diverse situations. Notably, all of the studies in this review had taken the etic approach by adopting measures and theoretical framework developed in the West as a starting point for understanding Singaporean parenting. As a result, none of these studies had identified any indigenous parenting concepts, unlike in other cultures such as Japan (e.g., amae), and among the ethnic Chinese (e.g., shaming; guan).

Apart from informing directions for future research, the findings of this review also provided a key take-away on the adoption of parenting intervention programmes that have been developed in Western contexts. Given that authoritative parenting practices are found to be beneficial to children's development in Singapore, interventions that promote authoritative parenting practices may still be relevant and useful. However, practitioners will need to be mindful of how "sub-optimal" practices may not necessarily yield negative outcomes.

Although practitioners would benefit from knowing under what circumstance (e.g., ethnicity, socioeconomic status or the age of the child) "sub-optimal" practices may confer benefits, there is insufficient information from the current review that would allow us to make a recommendation. This is because only one study (Ang, 2006) had explicitly compared ethnic differences in relation to parenting and children's developmental outcome, one other study examined age differences (Shin et al., 2020), and none looked at the effects of socioeconomic status. Hence, further research is needed to identify specific situations where children may benefit from stricter parenting that resembles authoritarianism. For example, past research has shown that children from lower-income families tended to perform better in school when parents exercised stricter control (Leung et al., 1998). Regardless of contextual factors, interventions would need to be subjected to regular evaluations to ensure that they continue to remain efficacious across time and developmental phases. 


\section{Conclusion}

This review has shown that parenting practices should be examined in the context of the emotional meaning and intentions conveyed through parenting styles, as the latter may impact the interpretation and effects of those practices. Although parents are almost always a child's first socialisation agents, children are likely to be cared for by multiple caregivers. In Singapore, like in some other Asian societies, extended family members such as grandparents are often the main caregivers of children (Thang et al., 2011). Parental influence therefore only captures one aspect of the child socialisation process, which may explain the small effect sizes typically observed in local parenting research. Adopting a broader approach would paint a more complete picture of the multiple spheres of influence a child experiences in Singapore. 


\section{References}

Abubakar, A., Van de Vijver, F. J. R., Suryani, A. O., Handayani, P., \& Pandia, W. S. (2015). Perceptions of parenting styles and their associations with mental health and life satisfaction among urban Indonesian adolescents. Journal of Child and Family Studies, 24(9), 2680-2692. https://doi.org/10.1007/s10826-014-0070-X

*Ang, R. P. (2006). Effects of parenting style on personal and social variables for Asian adolescents. American Journal of Orthopsychiatry, 76(4), 503-511. https://doi.org/10.1037/0002-9432.76.4.503

*Ang, R. P., \& Goh, D. H. (2006). Authoritarian parenting style in Asian societies: A clusteranalytic investigation. Contemporary Family Therapy, 28(1), 131-151. https://doi.org/10.1007/s10591-006-9699-y

Aunola, K., \& Nurmi, J. E. (2005). The role of parenting styles in children's problem behavior. Child Development, 76(6), 1144-1159. https://doi.org/10.1111/j.1467$\underline{8624.2005 .00840 . x-11}$

Barber, B. K., Olsen, J. E., \& Shagle, S. C. (1994). Associations between parental psychological and behavioral control and youth internalized and externalized behaviors. Child Development, 65(4), 1120-1136. https://doi.org/10.1111/j.14678624.1994.tb00807.x

Barber, B. K., Stolz, H. E., Olsen, J. A., Collins, W. A., \& Burchinal, M. (2005). Parental support, psychological control, and behavioral control: Assessing relevance across time, culture, and method. Monographs of the Society for Research in Child Development, 70(4), 1-13. https://www.jstor.org/stable/3701442

Baumrind, D. (1966). Effects of authoritative parental control on child behavior. Child Development, 887-907. https://doi.org/10.2307/1126611 
Bornstein, M. H. (2015). Children's parents. In M. H. Bornstein, T. Leventhal, \& R. M. Lerner (Eds.), Handbook of Child Psychology and Developmental Science (7th ed., pp. 55-132). John Wiley \& Sons, Inc. https://doi.org/10.1002/9781118963418.childpsy403

Buri, J. R. (1991). Parental authority questionnaire. Journal of Personality Assessment, 57(1), 110-119. https://doi.org/10.1207/s15327752jpa5701_13

Chao, R. K. (1994). Beyond parental control and authoritarian parenting style: Understanding Chinese parenting through the cultural notion of training. Child Development, 65, 1111-1119. https://doi.org/10.1111/j.1467-8624.1994.tb00806.x

Chao, R. K. (2001). Extending research on the consequences of parenting style for Chinese Americans and European Americans. Child Development, 72(6), 1832-1843. https://doi.org/10.1111/1467-8624.00381

Chao, R. K., \& Tseng, V. (2002). Parenting of Asians. In M. H. Bornstein (Ed.), Handbook of parenting (2nd ed., Vol. 4, pp. 59-93). Lawrence Erlbaum Associates, Publishers.

Cheah, C. S. L., Li, J., Zhou, N., Yamamoto, Y., \& Leung, C. Y. Y. (2015). Understanding Chinese immigrant and European American mothers' expressions of warmth. Developmental Psychology, 51(12), 1802-1811. https://doi.org/10.1037/a0039855

*Chen, V. H. H., \& Chng, G. S. (2016). Active and restrictive parental mediation over time: Effects on youths' self-regulatory competencies and impulsivity. Computers \& Education, 98, 206-212. https://doi.org/10.0.3.248/j.compedu.2016.03.012

Chen, X., Liu, M., \& Li, D. (2000). Parental warmth, control, and indulgence and their relations to adjustment in Chinese children: A longitudinal study. Journal of Family Psychology, 14(3), 401-419. https://doi.org/10.1037/0893-3200.14.3.401

*Cheung, H. S., \& Elliott, J. M. (2016). Measuring maternal sensitivity: Cultural variations in the measurement of emotional availability. Child Development, 87(3), 898-915. https://doi.org/10.1111/cdev.12519 
Cheung, H. S., \& Hawkins, R. (2014). Childcare and parenting practices in Singapore: A comparison of fathers' and mothers' involvement. Journal of Tropical Psychology, 4(e10), 1-12. https://doi.org/10.1017/jtp.2014.10

Cheung, H. S., \& Sim, T. N. (2017). Social support from parents and friends for Chinese adolescents in Singapore. Youth \& Society, 49(4), 548-564. https://doi.org/10.1177/0044118X14559502

*Chew, E. \& Wang, J. (2008). Perceptions of parental autonomy support and control, and aspirations of student athletes in Singapore. In M. Chia \& J. Chiang (Eds.), Sport Science and Studies in Asia (pp. 231-248). Taiwan: World Scientific. https://doi.org/10.1142/9789814304092_0015

*Chng, G. S., Li, D., Liau, A. K., \& Khoo, A. (2015). Moderating effects of the family environment for parental mediation and pathological internet use in youths. Cyberpsychology, Behavior, and Social Networking, 18(1), 30-36. https://doi.org/10.1089/cyber.2014.0368

*Chong, W. H., \& Chan, C. S. (2015). The mediating role of self-talk between parenting styles and emotional intelligence: An Asian perspective with Singaporean adolescents. International Perspectives in Psychology, 4(3), 195-208. https://doi.org/10.1037/ipp0000034

*Choo, H., Sim, T., Liau, A. K., Gentile, D. A., \& Khoo, A. (2015). Parental influences on pathological symptoms of video-gaming among children and adolescents: A prospective study. Journal of Child and Family Studies, 24(5), 1429-1441. https://doi.org/10.1007/s10826-014-9949-9

Cowden, T., Cummings, G., \& Profetto-Mcgrath, J. (2011). Leadership practices and staff nurses' intent to stay: A systematic review. Journal of Nursing Management, 19(4), 461-477. https://doi.org/10.1111/j.1365-2834.2011.01209.x 
*Cui, Y., Zhang, D., \& Leung, F. K. (2021). The influence of parental educational involvement in early childhood on 4th grade students' mathematics achievement. Early Education and Development, 32(1), 113-133. https://doi.org/10.1080/10409289.2019.1677131

Darling, N., \& Steinberg, L. (1993). Parenting style as context: An integrative model. Psychological Bulletin, 113(3), 487-496. https://doi.org/10.1037//0033-2909.113.3.487 Department of Statistics. (2020). Population Trends, 2020. Retrieved from https://www.singstat.gov.sg/-/media/files/publications/population/population2020.pdf Dwairy, M. A. (2008). Parental inconsistency versus parental authoritarianism: Associations with symptoms of psychological disorders. Journal of Youth and Adolescence, 37(5), 616-626. https://doi.org/10.1007/s10964-007-9169-3

Education GPS, OECD (n.d.). Singapore: Student Performance (PISA 2018). Retrieved from https://gpseducation.oecd.org/CountryProfile?plotter=h5\&primaryCountry=SGP\&tresh $\underline{\text { old }=5 \& \text { topic }=\mathrm{PI}}$

Gauvain, M., \& Parke, R. D. (2010). Socialization. In M. H. Bornstein (Ed.), Handbook of cultural developmental science (p. 239-258). Psychology Press.

Guttman, H. A. (1991). Systems theory, cybernetics, and epistemology. In A. S. Gurman \& D. P. Kniskern (Eds.), Handbook of family therapy (Vol. 2, pp. 41-62). New York: Brunner/Mazel.

Hoeve, M., Dubas, J. S., Eichelsheim, V. I., van der Laan, P. H., Smeenk, W., \& Gerris, J. R. M. (2009). The relationship between parenting and delinquency: A meta-analysis. Journal of Abnormal Child Psychology, 37, 749-775. https://doi.org/10.1007/s10802$\underline{009-9310-8}$ 
*Hong, R. Y., Lee, S. S., Chng, R. Y., Zhou, Y., Tsai, F. F., \& Tan, S. H. (2016).

Developmental trajectories of maladaptive perfectionism in middle childhood. Journal of Personality, 85(3), 409-422. https://doi.org/10.1111/jopy.12249

Hurley, C. M., Teo, W. J., Kwok, J., Seet, T., Peralta, E., \& Chia, S. Y. (2016). Diversity from within: The impact of cultural variables on emotion expressivity in Singapore. International Journal of Psychological Studies, 8(3), 50. https://doi.org/10.5539/ijps.v8n3p50

Jiow, H. J., Lim, S. S., \& Lin, J. (2017). Level up! Refreshing parental mediation theory for our digital media landscape. Communication Theory, 27(3), 309-328. https://doi.org/10.1111/comt.12109

Khaleque, A. (2013). Perceived parental warmth, and children's psychological adjustment, and personality dispositions: A meta-analysis. Journal of Child and Family Studies, 22(2), 297-306. https://doi.org/10.1007/s10826-012-9579-Z

Leung, K., Lau, S., \& Lam, W.-L. (1998). Parenting styles and academic achievement: A cross-cultural study. Merrill-Palmer Quarterly, 44(2), 157-172. https://www.jstor.org/stable/23093664

Li, Y., Costanzo, P. R., \& Putallaz, M. (2010). Maternal socialization goals, parenting styles, and social-emotional adjustment among Chinese and European American young adults: Testing a mediation model. The Journal of Genetic Psychology, 171(4), 330-362. https://doi.org/10.1080/00221325.2010.505969

*Liau, A. K., Khoo, A., \& Ang, P. H. (2008). Parental awareness and monitoring of adolescent Internet use. Current Psychology, 27(4), 217-233. https://doi.org/10.1007/s12144-008-9038-6 
*Liau, A. K., Khoo, A., \& Hwaang, P. (2005). Factors influencing adolescents engagement in risky internet behavior. CyberPsychology \& Behavior, 8(6), 513-520. https://doi.org/10.1089/cpb.2005.8.513

*Liu, C., Ang, R. P., \& Lwin, M. O. (2013). Cognitive, personality, and social factors associated with adolescents' online personal information disclosure. Journal of Adolescence, 36(4), 629-638. https://doi.org/10.1016/j.adolescence.2013.03.016

*Liu, C., Ang, R. P., \& Lwin, M. O. (2016). Influences of narcissism and parental mediation on adolescents' textual and visual personal information disclosure in Facebook. Computers in Human Behavior, 58, 82-88. https://doi.org/10.1016/j.chb.2015.12.060

Livingstone, S., \& Helsper, E. J. (2008). Parental mediation of children's internet use. Journal of Broadcasting \& Electronic Media, 52(4), 581-599. https://doi.org/10.1080/08838150802437396

*Luo, W., Aye, K. M., Hogan, D., Kaur, B., \& Chan, M. C. Y. (2013). Parenting behaviors and learning of Singapore students: The mediational role of achievement goals. Motivation and Emotion, 37(2), 274-285. https://doi.org/10.1007/s11031-012-9303-8

*Luo, W., Ng, P. T., Lee, K., \& Aye, K. M. (2016). Self-efficacy, value, and achievement emotions as mediators between parenting practice and homework behavior: A controlvalue theory perspective. Learning and Individual Differences, 50, 275-282. https://doi.org/10.1016/j.lindif.2016.07.017

Lwin, M. O., Stanaland, A. J., \& Miyazaki, A. D. (2008). Protecting children's privacy online: How parental mediation strategies affect website safeguard effectiveness. Journal of Retailing, 84(2), 205-217. https://doi.org/10.1016/j.jretai.2008.04.004

Maccoby, E., \& Martin, J. (1983). Socialization in the context of the family: Parent-child interaction. In P. H. Mussen (Ed.), Handbook of child psychology (pp. 1-101). New York: Wiley. 
Moher, D., Liberati, A., Tetzlaff, J., Altman, D. G., \& Prisma Group. (2009). Preferred reporting items for systematic reviews and meta-analyses: the PRISMA statement. PLoS Medicine, 6(7), e1000097. https://doi.org/10.1371/journal.pmed.1000097

Ng, F. F., Pomerantz, E. M., \& Deng, C. (2014). Why are Chinese mothers more controlling than American mothers? "My child is my report card." Child Development, 85(1), 355369. https://doi.org/10.1111/cdev.12102

*Ong, M. Y., Eilander, J., Saw, S. M., Xie, Y., Meaney, M. J., \& Broekman, B. F. (2018). The influence of perceived parenting styles on socio-emotional development from prepuberty into puberty. European Child \& Adolescent Psychiatry, 27(1), 37-46. https://doi.org/10.1007/s00787-017-1016-9

*Pang, J. S., Ang, R. P., Kom, D. M., Tan, S. H., \& Chiang, A. Q. (2013). Patterns of Reactive and Proactive Aggression in Young Adolescents in Singapore. Social Development, 22(4), 794-812. https://doi.org/10.1111/sode.12024

Pinquart, M. (2016). Associations of parenting styles and dimensions with academic achievement in children and adolescents: A meta-analysis. Educational Psychology Review, 28(3), 475-493. https://doi.org/10.1007/s10648-015-9338-y

Pinquart, M., \& Kauser, R. (2018). Do the associations of parenting styles with behavior problems and academic achievement vary by culture? Results from a meta-analysis. Cultural Diversity and Ethnic Minority Psychology, 24(1), 75-100. https://doi.org/10.1037/cdp0000149

Rohner, R. P., Khaleque, A., \& Cournoyer, D. E. (2005). Parental Acceptance-Rejection: Theory, Methods, Cross-Cultural Evidence, and Implications. Ethos, 33(3), 299-334. https://doi.org/10.1525/eth.2005.33.3.299

Rothbaum, F., \& Kakinuma, M. (2004). Amae and attachment: Security in cultural context. Human Development, 47, 34-39. https://doi.org/10.1159/000075368 
Ryan, R. M., \& Deci, E. L. (2000). Self-determination theory and the facilitation of intrinsic motivation, social development, and well-being. American Psychologist, 55(1), 68-78. https://doi.org/10.1037/0003-066X.55.1.68

*Sha, L., Looi, C. K., Chen, W., Seow, P., \& Wong, L. H. (2012). Recognizing and measuring self-regulated learning in a mobile learning environment. Computers in Human Behavior, 28(2), 718-728. https://doi.org/10.1016/j.chb.2011.11.019

*Shin, W., \& Kang, H. (2016). Adolescents' privacy concerns and information disclosure online: The role of parents and the Internet. Computers in Human Behavior, 54, 114123. https://doi.org/10.1016/j.chb.2015.07.062

*Shin, W., \& Lwin, M. O. (2017). How does "talking about the Internet with others" affect teenagers' experience of online risks? The role of active mediation by parents, peers, and school teachers. New Media \& Society, 19(7), 1109-1126. https://doi.org/10.1177/1461444815626612

*Shin, W., Lwin, M. O., Yee, A. Z., \& Kee, K. M. (2020). The role of socialization agents in adolescents' responses to app-based mobile advertising. International Journal of Advertising, 39(3), 365-386. https://doi.org/10.1080/02650487.2019.1648138

*Sim, T. N. (2000). Adolescent psychosocial competence: The importance and role of regard for parents. Journal of Research on Adolescence, 10(1), 49-64. https://doi.org/10.1207/SJRA1001_3

*Sim, T. N., \& Chin, J. E. (2014). Do mothers' and fathers' authoritative and authoritarian parenting interact? An exploration on schooling aspects with a Singapore adolescent sample. Youth \& Society, 46(2), 286-300. https://doi.org/10.1177/0044118X12441188

*Sim, T. N., \& Ong, L. P. (2005). Parent physical punishment and child aggression in a Singapore Chinese preschool sample. Journal of Marriage and Family, 67(1), 85-99. https://doi.org/10.1111/j.0022-2445.2005.00007.x 
*Sim, T. N., \& Singh, R. (1991). Peer and maternal factors in the manifestation of conduct problems. Psychologia, 34, 164-170.

Steinberg, L. (2001). We know some things: Parent-adolescent relationships in retrospect and prospect. Journal of Research on Adolescence, 11(1), 1-19. https://doi.org/10.1111/1532-7795.00001

Steinberg, L., Lamborn, S. D., Darling, N., Mounts, N. S., \& Dornbusch, S. M. (1994). Overtime changes in adjustment and competence among adolescents from authoritative, authoritarian, indulgent, and neglectful families. Child Development, 65(3), 754-770. https://doi.org/10.2307/1131416

Stewart, S. M., Bond, M. H., Kennard, B. D., Ho, L. M., \& Zaman, R. M. (2002). Does the Chinese construct of guan export to the West? International Journal of Psychology, 37, 74-82. https://doi.org/10.1080/00207590413000162

*Stright, A. D., \& Yeo, K. L. (2014). Maternal parenting styles, school involvement, and children's school achievement and conduct in Singapore. Journal of Educational Psychology, 106(1), 301. https://doi.org/10.1037/a0033821

Thang, L. L., Mehta, K., Usui, T., \& Tsuruwaka, M. (2011). Being a good grandparent: Roles and expectations in intergenerational relationships in Japan and Singapore. Marriage and Family Review, 47(8), 548-570. https://doi.org/10.1080/01494929.2011.619303

Wang, Q., Pomerantz, E. M., \& Chen, H. (2007). The role of parents' control in early adolescents' psychological functioning: A longitudinal investigation in the United States and China. Child Development, 78(5), 1592-1610. https://doi.org/10.1111/j.1467$\underline{8624.2007 .01085 . x}$

Ying, L., Yan, Q., Shen, X., Jia, X., \& Lin, C. (2019). Economic pressure and loneliness in migrant children in China: The mediating roles of parent-child communication and 
parental warmth. Child Psychiatry \& Human Development, 50(1), 142-149. https://doi.org/10.1007/s10578-018-0827-3

Zhang, W., Wei, X., Ji, L., Chen, L., \& Deater-Deckard, K. (2017). Reconsidering parenting in Chinese culture: Subtypes, stability, and change of maternal parenting style during early adolescence. Journal of Youth and Adolescence, 46(5), 1117-1136.

https://doi.org/10.1007/s10964-017-0664-X 